\title{
Endoskopik retrograd kolanjiyopankreatografinin endikasyonları, sonuçları ve komplikasyonları: Doğu Karadeniz'deki üçüncü basamak bir merkezin 3 yıllık verileri
}

\author{
Indications, results, and complications of endoscopic retrograde cholangiopancreatography: 3-year \\ data of a third-level center in the Eastern Black Sea Region
}

\author{
(D) Sami FIDAN, (D) Arif Mansur COŞAR \\ Karadeniz Teknik Üniversitesi, Tıp Fakültesi, Gastroenteroloji Bilim Dalı, Trabzon
}

\begin{abstract}
Giriş ve Amaç: Bu çalışmanın amacı merkezimizde yapılan endoskopik retrograd kolanjiyopankreatografi işlemlerinin endikasyon, teknik başarı ve sonuçlarını gözden geçirmektir. Gereç ve Yöntem: Karadeniz Teknik Üniversitesi Tıp Fakültesi Hastanesi, endoskopi ünitesinde Şubat 2017- Şubat 2020 tarihleri arasında endoskopik retrograd kolanjiyopankreatografi yapılan ardışık 524 hastanın sonuçları retrospektif olarak değerlendirildi. Her prosedürden önce hastalardan resmi yazılı onay alındı. Bulgular: Çalışmamızda 524 hastaya toplam 620 endoskopik retrograd kolanjiyopankreatografi işlemi gerçekleştirilmiştir. Hastaların 285'i (\%54.3) kadın, 239'u (\%45.6) erkek olup yaş ortalaması 64.5 (18103) idi. Hastaların \%97.8'inde endoskopik retrograd kolanjiyopankreatografi terapötik amaçla yapıldı. En sık endikasyon koledokolitiyazis (\%68.5) ve safra yollarında dilatasyon ve kolestaz bulgularının olması (\%20.8) idi. Hastaların 506'sında (\%96.6) başarılı selektif koledok kanülasyonu sağlandı ve bunların 32'sinde (\%7.8) iğne uçlu sfinkterotom ile ön kesi yapıldı. En sık tespit edilen bulgular koledokolitiyazis (\%61.8), koledok dilatasyonu veya benign biliyer stenoz (\%12.2) ve malign biliyer stenoz (\%8.0) idi. En sık yapılan terapötik işlemler endoskopik sfinkterotomi 450 (\%85.8), balon veya basket ile taş çıkarma 263 (\%50.2) ve stent yerleştirilmesi 158 (\%30.2) idi. Genel komplikasyon oranı \%4.9 olup en sık görüleni \%2.3 ile pankreatit idi. Serimizde 2 hastada (\%0.4) mortalite gelişti. Sonuç: Endoskopik retrograd kolanjiyopankreatografi ciddi komplikasyon riski taşımasına rağmen uygun endikasyonda yapıldığında pankreatobiliyer hastalıkların tedavisinde etkili ve güvenli bir yöntemdir. Endoskopik retrograd kolanjiyopankreatografi ilişkili morbidite ve mortaliteyi azaltmak için olası komplikasyonların erken tanısı ve uygun yönetimi çok önemlidir.
\end{abstract}

Anahtar kelimeler: ERCP, endoskopik retrograd kolanjiyopankreatografi, endoskopik sfinkterotomi

\section{GíRiş}

Endoskopik retrograd kolanjiyopankreatografi (ERCP) çeşitli pankreatobiliyer hastalıkların tanı ve tedavisinde yaklaşık 50 yıldır kullanılan, uzun bir öğrenme eğrisi olan ve teknik olarak görece zor bir işlemdir (1). ERCP başlangıçta tanısal bir işlem olarak kullanılmasına rağmen son 30 yılda tanısal ERCP yerini çoğunlukla manyetik rezonans

İletişim: Sami FIDAN

Karadeniz Teknik Üniversitesi, Tıp Fakültesi, Gastroenteroloji Bilim Dalı 61080, Trabzon • Tel: +90 4623775550 • Faks: +90 4623252270 E-mail: fidansami@yahoo.com
Background and Aims: The aim of this study was to review the indications, technical success, and results of endoscopic retrograde cholangiopancreatography in our center. Materials and Methods: The results of 524 patients who underwent consecutive endoscopic retrograde cholangiopancreatography between February 2017 and February 2020 in the endoscopy unit of Karadeniz Technical University, Faculty of Medicine, were evaluated retrospectively. Formal written consent was obtained from all patients prior to each procedure. Results: A total of 620 endoscopic retrograde cholangiopancreatography procedures were performed in 524 patients. Two hundred eighty five of the patients (54.3\%) were female and 239 (45.6\%) male, with an average age of 64.5 (18103). In $97.8 \%$ of the patients, endoscopic retrograde cholangiopancreatography was conducted for therapeutic purposes. Choledocholithiasis (68.5\%) and dilatation and cholestasis findings in the biliary tract (20.8\%) were the most common endoscopic retrograde cholangiopancreatography indications. Successful selective common bile duct cannulation was achieved in 506 of the patients (96.6\%), and precut sphincterotomy with needle knife sphincterotomy was performed in 32 (7.8\%) of them. The most common findings were choledocholithiasis (61.8\%), common bile duct dilatation, or benign (12.2\%) and malignant (8.0\%) biliary stenosis. On the other hand, the most common therapeutic procedures were endoscopic sphincterotomy in 450 patients (85.8\%), stone extraction with balloon or basket in 263 (50.2\%), and stent placement in 158 (30.2\%). The overall complication rate was $4.9 \%$, and the most frequent complication was pancreatitis with a rate of $2.3 \%$. In this series, two patients (0.4\%) died. Conclusion: Despite the possibility of severe complications, endoscopic retrograde cholangiopancreatography is an efficient and safe procedure for the treatment of pancreaticobiliary diseases when done with appropriate indications. Early diagnosis and effective treatment of potential complications are very important to reduce endoscopic retrograde cholangiopancreatography related morbidity and mortality.

Key words: $E R C P$, endoscopic retrograde cholangiopancreatography, endoscopic sphincterotomy

gibi radyolojik görüntüleme yöntemlerine bırakmış ve artık neredeyse tamamen terapötik amaçla yapılmaktadır $(2,3)$. ERCP günümüzde daha çok safra kanalı taşlarının çıkarıması, malign ya da benign darlıklarda stent yerleştirilmesi ve safra kesesi veya safra kanalı ameliyatlarından sonra ortaya çıkan komplikasyonların tedavisi için kullanılFidan S, Coşar AM. Indications, results, and complications of endoscopic
retrograde cholangiopancreatography: 3-year data of a third-level center in the retrograde cholangiopancreatography: 3-year data of a third-level center in the
Eastern Black Sea Region. The Turkish Journal of Academic Gastroenterology 2020;19:129-135. DOI: 10.17941/agd.836604

Geliş Tarihi: 23.11.2020 • Kabul Tarihi: 28.11.2020 
maktadır. Invaziv bir girişim olması nedeniyle literatürde \%10'lara ulaşan ERCP ilişkili komplikasyonlar bildirilmiştir $(4,5)$. ERCP'nin en sık görülen komplikasyonları pankreatit, kanama, kolanjit, kolesistit ve perforasyondur $(4,5)$. ERCP ile ilişkili komplikasyonları azaltmak için risk faktörlerinin çok iyi bilinmesi ve uygun endikasyonlarda ERCP yapılması önerilmektedir (5). Ülkemizde ve tüm dünyada ERCP endikasyonları ve sonuçları ile ilgili birçok çalışma olmasına rağmen Doğu Karadeniz Bölgesinde bu konu ile ilgili bir çalışma bulunmamaktadır (6-12). Bu çalışmada Karadeniz Teknik Üniversitesi Tıp Fakültesi Gastroenteroloji Bilim Dalı endoskopi ünitesinde ERCP yapılan hastaların sonuçlarını değerlendirmek amaçlanmıştır.

\section{GEREÇ ve YÖNTEM}

Bu çalışmaya Karadeniz Teknik Üniversitesi Tıp Fakültesi Gastroenteroloji Bilim Dalı endoskopi ünitesinde Şubat 2017- Şubat 2020 tarihleri arasında ERCP yapılan hastalar alındı. On sekiz yaşın altındakiler ve yeterli verisi olmayan hastalar çalışma dışı bırakıldı. ERCP yapılmadan önce hastaların anamnezleri alındı ve fizik muayeneleri yapıldı. Işlem öncesi hastaların demografik özellikleri, laboratuvar ve radyolojik bulguları oluşturulan ERCP takip formuna kaydedildi. Ayrıca hastaların alışkanlıkları, komorbit hastaııkları, geçirmiş olduğu operasyonlar, kullandıkları ilaçlar, American Society of Anesthesiologists (ASA) skoru, ERCP endikasyonu, allerji öyküsü, ERCP bulguları ve işlemle ilgili komplikasyonlar takip formuna kayıt edildi. Hastalar yapılacak işlem ve riskleri hakkında bilgilendirildi ve işlem öncesinde hastalardan yazıı onam alındı. İşlem sonrası ayaktan hastalar en az 3 saat süreyle endoskopi ünitesinde takip edilirken, kliniğe yatırılarak işlem yapılan hastalar ise en az 24 saat süreyle işlem sonrası komplikasyon için takip edildi. Ayaktan işlem yapılan hastalar olası komplikasyonlar için bilgilendirildi ve sorun yaşamaları durumunda acil servise başvurmaları önerildi. Hastaların hepsi bilinçli sedasyon altında işleme alındı. İşlem sırasında hastaların arteriyel oksijen satürasyonu, kalp atış hızı ve kan basıncı monitörize edildi. Çalışma Helsinki Bildirgesi ilkeleri doğrultusunda gerçekleştirilmiş ve Karadeniz Teknik Üniversitesi etik kurulu (No:2020-306 /06.11.2020) tarafından onaylanmıştır.

\section{Tanımlar}

ERCP işlemi ile ilgili olarak bir geceden fazla hastanede kalmayı gerektiren herhangi bir yan etki "ERCP komplikasyonu" olarak tanımlandı. Komplikasyonların şiddeti hastanede kalış süresine ve yapılan müdahaleye göre belirlendi. Hastaların ERCP ilişkili komplikasyondan dola- yı 2-3 gün plansız hastanede yatması hafif, dört ila 10 gün yatması orta, 10 günden fazla yatması, cerrahi ya da invaziv radyolojik müdahale gereksinimi veya ölümle sonuçlanan komplikasyonlar ise ciddi komplikasyon olarak tanımlandı $(4,5)$. ERCP ilişkili pankreatitin tanısı; uyumlu klinik ve/veya radyolojik bulguların varlığı ile birlikte serum amilaz düzeylerinin normal üst sınııın üç katından daha yüksek olması ile konuldu $(5,13)$. Klinik, laboratuvar ve radyolojik bulgulara dayanılarak hastalar revize Atlanta sınıflamasına göre hafif, orta ve şiddetli gruplara ayrıldı (13). Klinik veya endoskopik kanama bulgusu ile birlikte kan transfüzyonu ihtiyacı olmaması hafif kanama, 4 ünitenin altında kan transfüzyonu ihtiyacı olması veya anjiyografik ve/veya cerrahi tedavi gereksiniminin olmaması orta şiddette kanama, 5 ünitenin üzerinde kan transfüzyonu veya anjiyografik ve/veya cerrahi tedavi gereksiniminin olması şiddetli kanama olarak sınıflandırıldı (14). Hastalarda işlem sonrası ateş (>38 C), sarııık, sağ üst kadran ağrısı olması kolanjit, pozitif Murphy işareti ve tanı ile uyumlu görüntüleme bulgularının olması ise kolesistit olarak tanımlandı $(5,15)$. ERCP ile ilişkili perforasyon şüphesi durumunda radyolojik değerlendirme (bilgisayarı tomografi) yapıldı ve batın içi serbest hava görülmesi perforasyon olarak tanımlandı. Perforasyon sınıflaması, perforasyon yeri veya mekanizmasına göre yapıldı $(5,15)$.

Çalışma sonunda elde edilen verilerin istatistiksel analizinde Statistical Packagefor Social Sciences 16.0 (SPSS Inc.; Windows 16.0, Chicago, IL, USA) istatistik paket programı kullanıldı. Tüm hasta özellikleri, ortalama (maksimum-minimum) veya uygun olduğunda yüzdeler şeklinde ifade edilmiştir.

\section{BULGULAR}

Çalışmamızda 524 hastaya toplam 620 ERCP işlemi yapıldı. Çalışma süresince 72 hastaya birden fazla ERCP işlemi yapıldı (57 hastaya 2 defa, 8 hastaya 3 defa, 5 hastaya 4 defa, 2 hastaya 5 defa). Hastaların 285'i (\%54.3) kadın, 239'u (\%45.6) erkek olup yaş ortalaması 64.5 (18-103) idi. Çalışmaya alınan hastaların demografik ve klinik özellikleri Tablo 1'de verilmiştir. ERCP işlemi 443 (\%71.5) hastaya kliniğe yatıılarak, 177 (\%28.5) hastaya ise ayaktan yapıldı. ERCP öncesi ASA skorlarına göre yapılan değerlendirmede hastaların \%75'i ASA-2 ve ASA-3 grubundaydı. Hastalarda en sık görülen komorbit hastalıklar sırasıyla hipertansiyon (\%38.5), koroner arter hastalığı (\%20.2) ve diyabetti (\%12.9) (Tablo 1). Hastaların 305'i (\%58.2) Trabzon, 78'i (\%14.9) Giresun, 73'ü (\%13.9) Rize, 28'i (\%5.3) Gümüşhane ve 40'। (\%7.6) ise diğer illerden başvurdu. 
Tablo 1. ERCP yapılan 524 hastanın klinik ve demografik özellikleri

\begin{tabular}{|c|c|c|}
\hline Değişken & $\mathbf{n}$ & $\%$ \\
\hline Yaş [ortalama (min-mak)] & [64.5 (18-103)] & \\
\hline$<40$ & 67 & 12.8 \\
\hline $40-70$ & 220 & 41.9 \\
\hline$>70$ & 237 & 45.2 \\
\hline \multicolumn{3}{|l|}{ Cinsiyet } \\
\hline Kadın & 285 & 54.3 \\
\hline Erkek & 239 & 45.6 \\
\hline \multicolumn{3}{|l|}{ ERCP öncesi ASA skorları } \\
\hline ASA-1 & 74 & 14.1 \\
\hline ASA-2 & 197 & 37.6 \\
\hline ASA-3 & 196 & 37.4 \\
\hline ASA-4 & 57 & 10.9 \\
\hline \multicolumn{3}{|l|}{ Komorbid hastalıklar } \\
\hline Diyabet & 68 & 12.9 \\
\hline Hipertansiyon & 202 & 38.5 \\
\hline Koroner arter hastalığı & 106 & 20.2 \\
\hline Kronik akciğer hastalığı & 53 & 10.1 \\
\hline Kronik böbrek hastalığı & 17 & 3.2 \\
\hline Siroz & 4 & 0.8 \\
\hline \multicolumn{3}{|l|}{ ERCP endikasyonları } \\
\hline Radyolojik görüntülemede koledokolitiyazis bulgusu & 359 & 68.5 \\
\hline Safra yollarında dilatasyon ve kolestaz bulgularının olması & 109 & 20.8 \\
\hline Malign biliyer obstrüksiyon & 37 & 7 \\
\hline Safra kaçağı şüphesi & 15 & 2.9 \\
\hline Diğer nedenler & 4 & 0.7 \\
\hline
\end{tabular}

ASA: Amerikan Anestezistler Derneği skoru; ERCP: Endoskopik retrograd kolanjiyopankreatografi

ERCP için en yaygın endikasyon radyolojik görüntelemede koledokolitiyazis şüphesi (\%68.5) ve safra yollarında dilatasyon ve kolestaz bulgularının olması (\%20.8) idi (TabIo 1). ERCP yapilan 514 hasta normal mide anatomisine sahipken 10 hasta mide ameliyatı olmuştu (7 Bilroth-II, 3 Bilroth I gastrojejunostomi). Hastaların 506'sında (\%96.6) koledok kanülasyonu sağlandı (473'ünde ilk işlemde, 33 hastada ikinci işlemde). Onsekiz hastada koledok kanülasyonu sağlanamadı (5 pankreas karsinomu, 4 duodenal divertikül, 3 Bilroth II ameliyatlı hasta, 3 postbulber darlık ve koledok açılım anomalisi, 2 normal anatomili hasta, 1 ampulla vateri tümörü). Malignitesi olan 6 hastaya perkütan transhepatik kolanjiografi (PTK) ile drenaj ve/veya stentleme yapılırken benign ön tanılı olanlar daha ileri merkezlere refere edildi.

Hastaların büyük çoğunluğunda terapötik amaçla ERCP yapılırken sadece 15 (\%2.8) hastada tanısal ERCP uygu- lanmışı. Tanısal işlemler esas olarak periampuller tümör veya koledokta maling darlık şüphesi olan hastalarda patolojik örnekleme için yapıldı. Kırk yedi hastada (\%8.9) normal ERCP bulguları vardı. ERCP'de en sık görülen bulgular ise sırasıyla; koledokolitiyazis [n:324 (\%61.8)], koledok dilatasyonu veya benign biliyer stenoz [n:64 (\%12.2)], malign biliyer stenoz [n:42 (\%8.0)], biliyer yaralanma veya safra kaçağı şüphesi [n:12 (\%2.3)] ve diğer [n:35 (\%6.7)] şeklinde idi. En sık yapılan terapötik işlemler; sfinkterotomi [n:450 (\%85.8)] (biliyer sfinkterotomi [n:411 $(\% 78,4)]$, precut sfinkterotomi [n:32 $(\% 7,8)]$, pankreatik sfinkterotomi [n:7 (\%1.3)]), balon veya basket ile taş çıkarma [n:263 (\%50.2)], mekanik litotripsi [n:9 (\%1.7)], stent yerleştirilmesi [n:158 (\%30.2)] (biliyer stent yerleştirilmesi [n:140 (\%26.7)], pankreatik stent yerleştirilmesi [n:18 (\%3.4)]), biliyer balon dilatasyonu [n:12 (\%2.3)] şeklinde idi. Hastaların ERCP sonuçları Tablo 2 'de özetlenmiştir. 


\begin{tabular}{|c|c|c|}
\hline & $\mathbf{n}$ & $\%$ \\
\hline \multicolumn{3}{|l|}{ ERCP yapılma amacı } \\
\hline Tanısal & 15 & 2.8 \\
\hline Terapötik & 509 & 97.2 \\
\hline \multicolumn{3}{|l|}{ Uygulanan terapötik işlemler } \\
\hline Sfinkterotomi & 450 & 85.8 \\
\hline Biliyer & 411 & 78.4 \\
\hline Ön kesi & 32 & 7.8 \\
\hline Pankreatik & 7 & 1.3 \\
\hline Balonla taş çıkarma/Sıvazlama & 263 & 50.2 \\
\hline Mekanik litotripsi & 9 & 1.7 \\
\hline Stent yerleştirilmesi & 158 & 30.2 \\
\hline Biliyer & 140 & 26.7 \\
\hline Pankreatik & 18 & 3.4 \\
\hline Biliyer balon dilatasyonu & 12 & 2.3 \\
\hline \multicolumn{3}{|l|}{ ERCP bulguları } \\
\hline Normal ERCP bulguları & 47 & 8.9 \\
\hline Koledokolitiyazis & 324 & 61.8 \\
\hline Koledok dilatasyonu veya benign biliyer stenoz & 64 & 12.2 \\
\hline Malign biliyer stenoz & 42 & 8.0 \\
\hline Biliyer yaralanma veya safra kaçağı şüphesi & 12 & 2.3 \\
\hline Diğer & 35 & 6.7 \\
\hline
\end{tabular}

ERCP: Endoskopik retrograd kolanjiyopankreatografi

Hastaların 92'sinde (\%17.5) biliyer kanülasyon hedeflenirken önce pankreas kanülasyonu yapıldı (42 hastada 1 defa, 36 hastada 2, 13 hastada 3 defa, 1 hastada 4 defa). Bu hastaların 32'sinde (\%34.8) Wirsung kanalına kontrast kaçışı oldu ve bu hastaların 12'sine pankreatit profilaksisi için pankreatik stent takıldı. Pankreas kanülasyonu yapılan hastalardan sadece birinde pankreatit gelişti. Bu hasta pankreas kanalı 2 defa kanüle edilen, pankreas kanalına kontrast verilmeyen ve profilaktik pankreatik stent takılmayan 74 yaşında koledokolitiyazis tanılı erkek hasta idi. Konvansiyonel tedavi ile hasta düzeldi.

\section{ERCP Komplikasyonları}

ERCP yapılan hastaların 26'sında (\%4.9) ERCP sonrası komplikasyon gelişti. En sık görülen komplikasyonlar; pankreatit (n: 12, \%2.3) ve kanama (n:7, \%1.3) idi. Hastalarda gözlenen ERCP'ye bağlı komplikasyonlar Tablo 3'de özetlenmiştir. Akut pankreatit gelişen hastaların ikisinde şiddetli pankreatit, geri kalan 9 hastada hafif pankreatit gözlendi. Hafif pankreatitli hastalar uygun destekleyici medikal tedavi ile birkaç günde düzeldi ve sorunsuzca taburcu edildi. Şiddetli pankreatit gelişen hastalardan biri 2 haftanın üzerinde yatış gerektiren ve sonunda şifa ile sonuçlanan organ yetmezlikleri yaşarken diğer hasta nekrotizan pankreatit, batın içi apse ve organ yetmezliği sonucu kaybedildi. Sfinkterotomi sonrası kanama gelişen 7 hastanın sadece birinde 2 ünite kan transfüzyonu ihti-

\section{Tablo 3. ERCP komplikasyonları}

\begin{tabular}{|lcc|}
\hline Komplikasyonlar & $\mathbf{n}$ & $\%$ \\
\hline Genel & 26 & 4.9 \\
\hline Pankreatit & 12 & 2.3 \\
Hafif & 7 & 1.3 \\
Orta & 0 & 0 \\
Şiddetli & 2 & 0.4 \\
\hline Kanama & 7 & 1.3 \\
Hafif & 6 & 1.1 \\
Orta & 1 & 0.2 \\
\hline Şiddetli & 0 & 0 \\
\hline Kolanjit & 6 & 1.1 \\
\hline Kolesistit & 0 & 0 \\
\hline Perforasyon & 2 & 0.4 \\
\hline Portal ven trombozu & 1 & 0.2 \\
\hline Ölüm & 2 & 0.4 \\
\hline
\end{tabular}

ERCP: Endoskopik retrograd kolanjiyopankreatografi. 
yacı oldu. Bu hastanın ertesi gün yapılan kontrol endoskopisinde sfinkteretomi yerinde pıhtı olduğu ancak aktif kanamanın olmadığı görüldü. Kolanjit gelişen 6 hasta biliyer stent takılarak ve intravenöz antibiyotikler ile tedavi edildi. Bu hastalardan portal biliyopatisi olan 67 yaşında erkek hastada karaciğerde apse gelişmesi üzerine apse drenajı ve sonrasında uzun süre antibiyoterapi aldı. İi hastada sfinkterotomiye bağlı perforasyon gelişti (bir tanesi tip 2, diğeri tip 4 perforasyon). Bu hastalardan tip 2 perforasyon olan hastada koledoğa tam kaplı metal stent yerleştirildikten sonra oral alım kapatılarak antibiyoterapi uygulandı ve yatışının 3. gününde taburcu edildi. Diğer hastada sadece retroperitoneal hava izlendi ve bu hasta da sadece medikal ve semptomatik tedavi ile sorunsuzca taburcu edildi. Koledokolitiyazis nedeni ile işlem yapılan 78 yaşındaki kadın hastada işlemden sonra devam eden şiddetli karın ağrısı olması üzerine çekilen tomografide portal vende trombüs ve yaygın hepatik nekroz saptandı. Antikoagülan ve medikal tedaviye rağmen hasta yatışının 4. gününde kaybedildi.

\section{TARTIŞMA}

Terapötik ERCP pankreatobiliyer hastalıkların tedavisinde etkili ve güvenli bir yöntem olarak kabul edilmesine rağmen aynı zamanda zor ve ciddi komplikasyon riski taşıyan bir işlemdir. Hastanemiz bölgemizde 20 yılı aşkın süredir ERCP yapılan tek merkez olmakla birlikte son birkaç yılda bölgemizdeki diğer illerde de başarılı bir şekilde ERCP uygulanmaya başlanmışıır. Bu çalışmada son 3 yılda hastanemizde ERCP yapılan 524 hastanın sonuçlarını sunduk. Çalışmamız Doğu Karadeniz Bölgesindeki ERCP sonuçları veren ilk çalışmadır.

Koledok kanülasyonu, tüm endoskopik biliyer tedaviler için ön koşuldur, ancak bu her zaman kolayca başarılamaz. ERCP'de başarılı koledok kanülasyonu; ampulla vateriye erişime, endoskopik aksesuarların mevcudiyetine, kullanılan kanülasyon yöntemine ve işlem yapılan merkezin bu konudaki deneyimine bağlı olarak değişmekle birlikte literatürde \%82.6-98 arasında bildirilmiştir $(8,10,16)$. Çalışmamızda başarılı koledok kanülasyon oranı \%96.6 olup literatürle uyumlu idi. Kliniğimizde kılavuz önerilerinde olduğu gibi standart olarak kanülasyon işlemine kılavuz tel yüklü sfinkterotom ile başlanmaktadır. Uygun pozisyonda 5 deneme veya 5 dakikadan uzun sürede koledok kanülasyonu yapılamaması veya birden fazla istenmeyen pankreas kanalı kanülasyonu olması durumunda ön kesi yapılarak koledok kanülasyonu denenmektedir $(5,17)$. Tekrarlanan ve uzun süreli kanülasyon girişimleri ERCP'ye bağlı komplikasyon riskini arttırdığı için bu durumda alternatif kanülasyon yöntemlerine erken geçilmesi önerilmektedir (18). Çalışmamızda 32 (\%7.8) has- tada ön kesi yapılarak kanülasyon sağlandı. Literatürde çalışmamızla benzer olarak ön kesi yapılma oranları \%3.3 ile \%14.8 arasında bildirilmiştir (4,6-10). Çalışmalarda ön kesi yapılması durumunda başta kanama olmak üzere genel komplikasyon oranlarııı arttığı bildirilmesine rağmen bu konuda yapılan bir metaanalizde erken ön kesi yapmanın pankreatit oranlarını belirgin olarak azalttığı gösterilmiştir (19). Çalışmamızda ön kesi yapılan 32 hastanın hiçbirisinde ERCP ilişkili komplikasyon gelişmedi. Ön kesi yapılmasına rağmen koledok kanülasyonu sağlanamazsa; perkütan transhepatik veya cerrahi müdahale gibi daha invaziv alternatif müdahalelerden önce, birkaç gün sonra ERCP'nin tekrarlanması önerilmektedir $(17,18)$. Çalışmamızda ön kesi yapılmasına rağmen ilk işlemde başarılı koledok kanülasyonu sağlanamayan 51 hastanın 33'ünde (\%64.7) ikinci işlemde koledok kanülasyonu sağlandı.

Çalışmamızda en sık ERCP endikasyonu koledokolitiyazis şüphesi (\%63.9) ve ardından safra yollarında dilatasyon ve kolestaz bulgularının olması (\%20.8) idi. İşlem öncesi koledokolitiyazis şüphesi olan 359 hastanın sadece 242 'sinde (\%67.4) koledok taşı saptandı. Öte yandan işlem öncesi radyolojik görüntülemelerde safra yollarında dilatasyon ve kolestaz bulguları olmasına rağmen koledokolitiyazis olmayan 109 hastanın 49'unda (\%44.9) ERCP'de koledokolitiyazis veya safra çamuru saptandı. Ülkemizden yapılan çalışmalarda bizim çalışmamıza benzer olarak en sık ERCP endikasyonu (\%71-86.4) koledokolitiyazis veya kolestatik enzim artışı olarak bildirilmiştir (6-8). Ülkemiz dışında yapılan çalısmalar da bu bulguları destekler niteliktedir. Hindistan'da yapılan ve 1038 hastanın dahil edildiği retrospektif bir çalışmada en sık ERCP endikasyonu çalışmamıza benzer şekilde koledokolitiyazis (63.9\%) olarak bildirilmiştir (11). Benzer olarak Mariani ve arkadaşları tarafından yapılan, 18 merkezden 2388 hastanın prospektif olarak değerlendirildiği bir çalışmada en sık ERCP endikasyonu \%57 ile koledokolitiyazis idi.

ERCP ciddi komplikasyonları da olan bir işlem olduğu için işlem öncesinde hastalar ERCP gerekliliği açısından dikkatli bir şekilde değerlendirilmelidir. ERCP'ye bağı komplikasyonları azaltmanın en iyi yolu uygun endikasyonda ve tecrübeli kişilerce işlemlerin yapılmasıdır. Ayrıca potansiyel komplikasyonların erken tanınması ve uygun şekilde yönetilmesi, prosedürle ilişkili morbidite ve mortaliteyi azaltmak için kritik öneme sahiptir. Çalışmamızda genel komplikasyon oranı \%4.9 ve mortalite oranı ise \%0.4 idi. En sık görülen komplikasyon pankreatit (\%2.3) olup bunu kanama (\%1.3) takip ediyordu. Yapılan çalışmalarda ERCP'nin genel komplikasyon oranları \%5.9-10.8 ve mortalite oranları ise \%0.1-1.2 arasında bildirilmiştir $(4,6,10-12,20)$. Yapılan çalışmaların çoğunluğunda bulgularımıza benzer şekilde en sık görülen komplikasyon; 
pankreatit ve kanama olarak rapor edilmiştir. İki büyük metaanalizde ERCP sonrası pankreatit insidansı \%4.811.9 olarak bildirilmiştir $(21,22)$. Post-ERCP pankreatit gelişen hastalardaki mortalite ise \%0.1-0.7 arasında bildirilmiştir $(5,13)$. Çalışmamızda 7 (\%1.3) hastada pankreatit gelişti ve bunların bir tanesi şiddetli pankreatit nedeni ile kaybedildi. Kliniğimizde pankreatit için yüksek riskli işlemler dışında rutin olarak nonsteroid antiinflamatuvar ilaç kullanmamamıza rağmen pankreatit oranlarımız nispeten düşüktü. Yakın zamanda Kwak ve arkadaşları tarafından 1079 hastada yapılan retrospektif bir çalışmada ERCP sonrası pankreatit oranı \%1.7 olarak bildirilmiştir (4). Çalışmamızda 7 (\%1.3) hastada ERCP sonrası kanama gelişti ve bunlardan sadece birinde kan transfüzyonu ihtiyacı oldu. Literatürde ERCP sonrası kanama \%0.3-9.6 ve kanamaya bağlı mortalite ise \%0.04 oranında bildirilmiştir $(5,14)$. Suna ve arkadaşları tarafından 6552 hastanın retrospektif olarak değerlendirildiği tek merkezli bir çalışmada ERCP sonrası kanama \%1.23 olarak saptanmıştır (23). Çalışmamızda 6 (\%1.1) hastada kolanjit ve $2(\% 0.4)$ hastada ise perforasyon gelişti ve bu bulgular literatür ile uyumlu idi $(5,14)$.

\section{KAYNAKLAR}

1. McCune WS, Shorb PE, Moscovitz H. Endoscopic cannulation of the ampulla of Vater: a preliminary report. Ann Surg 1968;167:752-6.

2. Salerno R, Mezzina N, Ardizzone S. Endoscopic retrograde cholangiopancreatography, lights and shadows: Handle with care. World J Gastrointest Endosc 2019;11:219-30.

3. Moffatt DC, Yu BN, Yie W, Bernstein CN. Trends in utilization of diagnostic and therapeutic ERCP and cholecystectomy over the past 25 years: a population-based study. Gastrointest Endosc 2014;79:615-22.

4. Kwak N, Yeoun D, Arroyo-Mercado F, et al. Outcomes and risk factors for ERCP-related complications in a predominantly black urban population. BMJ Open Gastroenterol 2020;7:e000462.

5. Dumonceau JM, Kapral C, Aabakken L, et al. ERCP-related adverse events: European Society of Gastrointestinal Endoscopy (ESGE) Guideline. Endoscopy 2020;52:127-49.

6. Tunç N, Kılıç S, Şahin A, et al. Endoscopic retrograde cholangiopancreatography complications: frequency, contributing factors, and management. Endoscopy Gastrointestinal 2018;26:12-6.

7. Kıraç CO, Asıl M, Demir A. 4 yıllık endoskopik retrograd kolanjiopank-reatografi vakalarımızın retrospektif değerlendirilmesi. Genel Tıp Derg 2016;26:53-7.

8. Atamanalp SS, Yıldırgan Mi, Kantarcı A. Endoscopic retrograde cholangiopancreatography (ERCP): outcomes of 3136 cases over 10 years. Turk J Med Sci 2011;41:615-21.

9. Sarıtaş Ü, Gören İ, Şenol A. Terapotik ERCP komplikasyonları için risk faktörleri: Tek merkezli prospektif çalışma. Akademik Gastroenteroloji Dergisi 2006;5:163-8.

10. Mariani A, Segato S, Anderloni A, et al. Prospective evaluation of ERCP performance in an Italian regional database study. Dig Liver Dis 2019;51:978-84.
Çalışmamızın esas olarak retrospektif olmasından kaynaklanan bazı sınırlamaları bulunmaktadır. Bunlardan bir tanesi çalışmamızda gecikmiş ERCP komplikasyonları hakkında veri toplamak için standart bir yöntemimiz olmamasıdır. Bu nedenle ERCP komlikasyonu nedeniyle diğer hastanelere başvuran hastaların olabileceği göz ardı edilmemelidir. Çalışmamızın bir diğer kısıtlılığı ise işlem sırasında hastalar monitörize edilmesine rağmen bu sonuçların kaydedilmemiş olmasıdır. Bu nedenle işlem sırasındaki olası kardiyopulmoner komplikasyonlar bildirilemedi.

Sonuç olarak ERCP ciddi komplikasyon riski taşımasına rağmen pankreatobiliyer hastalıkların tedavisinde etkili ve güvenli bir yöntemdir. ERCP ilişkili morbidite ve mortaliteyi azaltmak için işlem öncesi hastaların endikasyon açısından dikkatli bir şekilde değerlendirilmesi, olası komplikasyonların erken tanısı ve uygun yönetimi önem arz etmektedir. ERCP yapılan her merkezin sonuçlarını bu esasa göre değerlendirmesi ve önlem alması gereklidir. Bu sonuçların paylaşılmasının da tecrübe paylaşımı açısından faydalı ve gerekli olduğu kanısındayız.

\section{"Tüm yazarlar herhangi bir çıkar çatışması olmadığı- nı beyan ederler."}

11. Choudhury BN, Deka UJ, Baruah BJ, et al. Indications, outcomes and complications of therapeutic endoscopic retrograde cholangiopancreatography procedures in a tertiary care centre in North East India. Int J Res Med Sci 2020;8:2606-11.

12. Jain PK, Vinay BN. Indications and complications of endoscopic retrograde cholangiopancreatography procedures in a tertiary care centre. Int J Adv Med 2016;3:838-41.

13. Banks PA, Bollen TL, Dervenis $C$, et al. Classification of acute pancreatitis-2012; revision of the Atlanta classification and definitions by international consensus. Gut 2013;62:102-11.

14. Cotton PB, Eisen GM, Aabakken L, et al. A lexicon for endoscopic adverse events: report of an ASGE workshop. Gastrointest Endosc 2010;71:446-54.

15. ASGE Standards of Practice Committee, Chandrasekhara $V$, Khashab MA, Muthusamy VR, et al. Adverse events associated with ERCP. Gastrointest Endosc 2017;85:32-47.

16. Sahar N, La Selva D, Gluck M, et al. The ASGE grading system for ERCP can predict success and complication rates in a tertiary referral hospital. Surg Endosc 2019;33:448-53.

17. Testoni PA, Mariani A, Aabakken L, et al. Papillary cannulation and sphincterotomy techniques at ERCP: European Society of Gastrointestinal Endoscopy (ESGE) Clinical Guideline. Endoscopy 2016;48:657-83.

18. Chen Q, Jin P, Ji X, Du H, Lu J. Management of difficult or failed biliary access in initial ERCP: A review of current literature. Clin Res Hepatol Gastroenterol 2019;43:365-72.

19. Sundaralingam P, Masson P, Bourke MJ. Early precut sphincterotomy does not increase risk during endoscopic retrograde cholangiopancreatography in patients with difficult biliary access: a meta-analysis of randomized controlled trials. Clin Gastroenterol Hepatol 2015;13:1722-9.e2. 
20. Basat O, Köklü S, Çiçek B, Parlak E, Şahin B. Endoskopik retrograd kolanjiopankreatografi komplikasyonlarr: Tek merkezli retrospektif çalışma. Akademik Gastroenteroloji Dergisi 2006;5:169-72.

21. Serrano JPR, de Moura DTH, Bernardo WM, et al. Nonsteroida anti-inflammatory drugs versus placebo for post-endoscopicretrograde cholangiopancreatography pancreatitis: a systematic review and meta-analysis. Endosc Int Open 2019;7:E477-86.
22. Matsubayashi CO, Ribeiro IB, de Moura DTH, et al. Is endoscopic balloon dilation still associated with higher rates of pancreatitis?: a systematic review and meta-analysis. Pancreas 2020;49:158-74.

23. Suna $N$, Ödemiş B, Dişibeyaz $S$, et al. Bleeding after endoscopic sphincterotomy: A single-center retrospective study. Endoscopy Gastrointestinal 2018;26:1-5. 